\title{
The Development of Consumer-Driven Human Services Information Technology Initiatives: The Lake County Indiana Experience
}

\author{
Thomas W. Pavkov and Charles Winer \\ Purdue University Calumet, USA
}

tpavkov@nwi.calumet.purdue.edu winer@calumet.purdue.edu

\begin{abstract}
The Family Access Project will deploy innovative community empowerment, education, consensus building, and information system development strategies to strengthen community, ensure the efficient and effective delivery of needed services, and address the unique needs of families requiring public assistance from a host of public and private agencies in Lake County. The goal of the project is to enhance community life through improved care coordination by linking new technologies to the human service delivery process. Upon completion, the project will assist in the enhancement of communitybased services through the development of rules of data transaction and data standards and the deployment of a secure messaging/document exchange network. By putting technology in the hands of consumers we also hope to impact the economic development and workforce readiness goals set forth in our community's welfare to work programs. These innovations will require educational innovations in order to facilitate the use of technology by both provider and consumer end-users. Proposed innovations include tutorials related to data standards development, peer train-the-trainer training in the development and use of technology to support service system reforms; and ongoing support through a technical assistance clearinghouse and help desk.
\end{abstract}

Keywords: human services, social services, information technology

\section{Introduction}

Both consumers and advocates in Lake County are working cooperatively to address the problems of pervasive poverty and quality of life in the region. Recently, the Child, Adolescent, and Family Branch of CMHS, SAMHSA awarded a five-year grant to fund the Child Mental Health Initiative (CMHI) in the county. In the CMHI project, case coordination is realized using an orchestrated 'wraparound team' approach to envelope the family and child with needed supports. Simultaneously, the Lake County Integrated Service Delivery Board (ISDB) is implementing a one-stop-shop approach for human service delivery across the county. In both initiatives, improved case coordination can be realized with

Material published as part of this journal, either on-line or in print, is copyrighted by the publisher of Informing Science. Permission to make digital or paper copy of part or all of these works for personal or classroom use is granted without fee provided that the copies are not made or distributed for profit or commercial advantage AND that copies 1) bear this notice in full and 2) give the full citation on the first page. It is permissible to abstract these works so long as credit is given. To copy in all other cases or to republish or to post on a server or to redistribute to lists requires specific permission and payment of a fee. Contact Editor@inform.nu to request redistribution permission. technology that facilitates virtual service integration. It is this approach that is articulated in the recently completed Lake County Human Services/Information Technology Mapping Project (MSITMP), a project commissioned by both consumer and provider stakeholders. The problems, solutions, and outcomes articulated at the person and system level are as follows. 


\section{Person Level Context}

\section{Person level problem}

Consumers in the community voice anxiety about their ability to penetrate a human service system that does not hear their voice. As such, many consumers are not knowledgeable about the range of services available to them, have limited ability to advocate on their own behalf, must navigate long and laborious referral and case-coordination processes, and lack direct communications links to those who coordinate services. They also face language and literacy barriers that exacerbate the problems associated with accessing services.

\section{Person level solution}

The proposed project provides consumers peer education, chat rooms for a way to build consensus, and instant messaging through a secure messaging/document exchange network in order to realize real time mutual support and communication to care-coordinators. The secure network will allow consumers to communicate with providers using secure e-mail, instant messaging, and digital document access. The network will also be integrated with an existing information and referral database already deployed in the county. Consumers will be assisted in the use of the technology by an extensive program of education and peer mentoring along with a computer recycling program designed to allow consumers to purchase low-cost PC workstations for use at home. Deployment of this solution will take place in the second year.

\section{System Level Context}

\section{System level problem}

As in most regions of the country, human service systems in northwest Indiana providing services to families and children are fragmented and isolated and do not have effective and efficient modalities of communication to facilitate coordinated and efficient case-management activities. This is a result of categorical streams of funding, the multiple systems servicing the same population (i.e. juvenile justice, education, child welfare, and mental health, Medicaid, TANF), and the discordance of these systems. As reported in the HSITMP, communication between providers exists between sectors on an informal, asneeded basis rather than through formalized and well-integrated processes. The absence of standards for information sharing and the technological infrastructure needed to facilitate such exchanges has rendered the services system incapable of managing its collective and ever increasing caseloads; allowed the services system to be less than responsive to the complexity of consumers' needs; and left consumers out of the process of monitoring their needs and accomplishments.

\section{System level solution}

The proposed project involves the development of the organizational structure needed to support the human services information infrastructure in the county. As an organizational change process, the development of this organizational structure will include the development of rules of data exchange, data standards, and the architectural standards needed to use internet technologies to support the secure transaction of data between local human service agencies, consumers, and key state agencies. The project will build on the local data standards proposed in by the HSITMP, rules of data exchange and data standards recently developed for the healthcare industry as part of the federal administrative simplification act (a subpart of the Health Insurance Portability and Accountability Act (HIPAA)) and California's Calinx project, and other state and federal standards. With the assistance of the Workgroup for the Computerization of Behavioral Health and Human Service Records, the project team will 
facilitate the development of these rules and standards using the repository of information compiled by the Workgroup. These rules and standards will then be implemented as part of the secure messaging/document exchange network solution.

\section{Innovation}

The distinguishing features of the proposed project involve its unique "consumercentric" approach harnessing internet-based technology to facilitate real time, virtual service coordination by facilitating interaction between three groups of individuals; providers to providers, providers to consumers and vice versa, and consumer to consumer. Furthermore, this project will build the most innovative and secure means of facilitating communication between these three groups. The creation of the secure document exchange network will incorporate interactive capacity along side a secure document-centric document exchange system. The project will design the system with the multilingual capacity needed to serve a culturally diverse populations. The website will be written at the $4^{\text {th }}$ grade level and the system will maintain accessibility functionality for individuals with challenges by using color variations, large fonts, symbols, and so on.

Given that many information technology projects fail because they do not adequately support end-users, the project will feature an extensive base of supports for both providers and consumers that will drive the change management process. The use of Workgroup resources separates this initiative from other human service infrastructure projects. In healthcare there are many data standards, conferencing, and training companies who keep their industry abreast of all regulatory changes and emerging standards. There exists no such entity in the behavioral health and human service arena other than the Workgroup. The Workgroup has established connections with all health care standards groups. The Workgroup will provide peer mentor and educational services to and in collaboration with local stakeholders. The Workgroup will establish a virtual consultation mechanism and data standards clearinghouse that will serve Indiana and have the potential to serve the nation at the same time. In sum, the Workgroup's involvement will assist in the development of a set of data rules and standards unique to human services while simultaneously assuring local end-user buy-in through support activities.

Given that most impoverished communities confront problems similar to those characterized in Lake County, four aspects of this project are highly replicable in other fragmented human service systems: the low-cost recycled computer program for consumers, the process for establishing the virtual network for other service systems of care, the process of educating and obtaining buy-in from end-users, the development of rules of data exchange and data standards that conform to state and federal regulations, and the security features of the secure document exchange network.

Many government entities share the frustration of limited data sharing across categorical programs serving common populations. Participants in the Comprehensive Community Mental Health Services for Children and their Families program (43 sites) and the Boost -4-Kids projects across the country confront common legal (state and federal mandates) and technical obstacles (e.g., linking old disparate legacy system) to the implementation of virtual networks and systems integration projects. The rules, standards, and technologies developed as part of this project will enjoy widespread deployment. For instance, there are 43 separate CMHS system of care projects across the country that share the same information infrastructure issues as the CMHI. The respective templates developed for use in Lake County will allow communities ripe for replication to experience the reality of integrated human service infrastructures.

From a technical aspect, the project will deploy technologies readily accessible and easily replicated in other locations. Given the nature of internet based technologies, the capacities developed during the course of this project will essentially allow a wide array of potential users to subscribe to the technology as a portfolio of services. As such, the diffusion potential of the project is only limited by the scale of 
information technology processing within a given location. In essence, the only requirements for enduser subscription are adoption of the rules of data exchange and data standards along with the technical capability of accessing the network using an internet service provider.

Experience has shown that it is not a given that people will use even the best-designed information systems. The implementation of new technologies is often plagued by lack of end-user buy-in and inadequate educational promotion and support services to maintain buy-in. Healtheon, the nation's leading e-commerce health solution has invested more than \$465 million into a marketing campaign and has offered another $\$ 400$ million dollars of free service to induce physicians to subscribe. Our project plans to address the need to develop buy-in by providing both local and national level supports and consultation in tandem with data system development. The Workgroup's organizational change strategy coupling consultation, peer train-the-trainer, and helpdesk /clearinghouse will provide the opportunity for others to use the same strategies elsewhere.

\section{Technical Approach}

The technical approach is designed to foster easy access by consumers and providers using low-cost internet-based technologies. Specifically, the project infrastructure will include an array of email gateway, email, webserver, and virtual private network servers located behind a firewall and array of routers/switches. The email gateway, email, and web servers will be linked in load balanced server array which will provide the high level of fault tolerance and redundancy required in the project. The array of network servers will reside behind a firewall server programmed to restrict access to only those having certificates allowing entry to the network. While security is maintained behind the firewall, the system will have the capacity to be integrated with additional capacity such as a centralized intake and/or case-coordination capacity at a later date.

Each subscriber to the secure document network is given a "room" within that network. Each human services consumer will be given a room within the network. Individual providers such as casemanagers, therapists, or social workers will subscribe to "rooms" as well. At the invitation of the consumer, case-managers', therapists', and social workers' "rooms" may become resident within the consumer's room. The co-location of providers' rooms within the consumer's room facilitates the virtual staffing over the secure messaging/document exchange network. The consumer is empowered in the human service delivery process by being able to monitor and communicate on issues related to ongoing case management activities. The installation will also support interactive tools such as immediate messaging and mutual support 'chat rooms' designed to enhance the mutual support and selfefficacy of human service consumers. The case coordinator will use the virtual staffing to facilitate case coordination processes. For instance, linkage to the information and referral database will allow case managers to monitor the referral process and to follow-up on services articulated in the individualized service plan. A tickler capability will also be built into the network to notify secondary providers of referrals to their agencies.

Access to the secure document exchange network will utilize a virtual private network operated from behind the network firewall. The virtual private network will use two levels of access using both a swipe card activated PIN number and a second level password. When the PIN scan occurs, the system sends an encrypted security process to the network for authentication. The authentication process is then matched against the card key data and validation is sent back to the local system, again encrypted. The information transacted over the internet will be protected using 128 bit encryption technology that meets or exceeds HCFA guidelines. Subscribers to the network will be required to provide the low-cost hardware and software needed to support secure communications to and from their PC workstations.

In order to use the secure document exchange network as an image documenting system, the subscribers will need to purchase a scanner for use with their PC workstations. Documents such as Individualized 
Service Plans may be shared between members of a "wraparound team" or any group of subscribers engaged in the coordination of integrated human services delivery. The subscription cost to the network will provide unlimited access to the internet as well as access to the virtual private network. The network security officer will generate the swipe cards used to access the system. Lost cards will be replaced for a nominal fee.

The proposed technical approach taken in this proposal is preferred for a number of reasons. First, the approach taken in this technical paradigm will meet or exceed federal security standards articulated by the Health Care Finance Administration (HCFA) in the transmission of data over the internet. Second, security concerns are addressed with the use of swipe card technology that acts as an external authorization referent for the subscriber. This is preferred over a "smart-card" or biometric approach as a costefficient security alternative.

The use of the secure document exchange network will also provide support for both electronic signature procurement and document imaging capability as these become more normative methods of sharing data. Given the process of informed consent and medical/human service record ownership, the proposed technical approach has the potential to revolutionize current protocols. Each transaction of data submitted into the secure document exchange network will be stored in either a digital image or binary format with an associated transaction code. By employing electronic signature capabilities, the system will enhance the process of obtaining signed consent for services. The document imaging capabilities will enhance the case coordination process for both providers and consumers.

The Workgroup will also deploy a website that is primarily intended to provide ongoing support for endusers. The website will maintain links to other data standards groups, other IT initiatives, and 'best practices' information related to information infrastructure. The Workgroup site will allow end-users to interact with each other and with Workgroup staff. This website will provide a forum for the exchange of reports, listserves, and mail distribution related to the use of technology in the human services. Links between the Workgroup website and the network website will allow end-users to access the electronic help desk and clearinghouse.

The scalability of the project is infinite and is only limited by the number of subscribers. The approach may be employed as a local solution maintained as a licensed product by a consortium of users as an application service provider (ASP). The network hardware may reside locally or at a remote sight. In terms of scalability, this type of exchange network is easily deployed at the county, regional, or state level. As the size of the subscriber base changes, the network may easily be modified to meet the new usage requirements. In terms of sustainability, the network will have the potential to recover costs at the end of the first year.

\section{Community Involvement}

\section{Partnerships}

The synergies developed through the completion of the HSITMP and the Lakenet project have spawned a strategic alliance for this project. The partners include Purdue University Calumet as the host and fiscal agent. Lead partners include the Indiana's Division of Family and Children, Lake County Public Library, Workforce Development Services of Lake County, Lake Area United Way, the Workgroup for the Computerization of Behavioral Health and Human Service records, and Indiana University Northwest. The Division of Family and Children funded the HSITMP and is involved in ongoing service integration efforts. The Lake County Library has provided over 30,000 individuals with internet training and continues to administer the Information and Referral Service (in cooperation with United Way) through its Lakenet internet portal. Workforce Development Services will provide housing for the hardware infrastructure. The Workgroup will serve as the change management partner as they assist in 
the education and training of end-users. The Workgroup is a nationally recognized non-profit organization committed to data standards development, privacy protection, and application of new technologies. The Workgroup has developed a model technical infrastructure and process for involving communities in the design, implementation, and evaluation of consumer-focused Internet-based information systems. Staff from Indiana University Northwest were partners in the HSITMP and will assist in the implementation of this effort.

\section{Involvement of the Community}

Our vision for the secure document exchange network is born out of a process of visioning and proposal development that has taken place in a number of forums in the six months prior to proposal submission. A series of presentations related to the HSITMP findings, including monthly Q and A's at the Welfare to Work Council meetings, have provided numerous opportunities for visioning about the use of technology in human services.

\section{Support for End-Users}

It is our belief that use of traditional direct education strategies would not have allowed us to take advantage of the wealth of knowledge that program participants have, and would additionally run the risk of insulting or alienating different participants at different times. Consequently, we sought a nonthreatening and empowering means of engaging system of care leaders in the movement toward consumer-focused Internet-based health and human service record-keeping systems. In this regard, peer consultation and mutual training programs have been proven to be an effective means of educating and inspiring such leaders. When accompanied by intensive action planning these experiences have been found to be exponentially more effective. Accordingly, the proposed project model has been purposely constructed to be interactive. Project participants do not just passively receive information through lecture format. Instead, they will actively engage in all phases of peer consultation model, often by becoming the teachers and leaders at these sessions.

Implementation of a peer consultation/train the trainer model is one of this project's primary engines of change and, as stated, will involve the co-leadership of Workgroup staff and local end-users. Due to limited funds available under this grant offering, we sought solutions that held the promise of doing more with less. Therefore, rather than expand the technological capacity of only a few Lake County agencies, we have chosen instead to plant the seeds that will emerge as expansive gardens of diverse, but complementary content. Seeds that will empower local systems and their key stakeholders with the information they will need to institute new public/private partnerships dedicated to creating state-of-the art information system infrastructures to support quality care delivery systems. In the end, the seeds sown in this project will grow into the talent needed to sustain the project into the new millennium.

The peer consultation will be enhanced via virtual and video consultation on a biweekly basis. The basis of selection for these interventions is the Workgroup prototype for a virtual consumer driven record keeping system. Family advocacy organizations' depictions of child, family, and community needs will drive the dialogue for full family and consumer involvement in the development of information system infrastructures. These opportunities may lead to academic and continuing education credit, or certification programs sponsored by the university.

\section{Reducing Disparities and the Digital Divide}

The Family Access Project will assist providing a bridge for many consumers of human services across the digital divide. Lake County with an estimated 1997 population of 479,339 is the most racially diverse county in the State of Indiana with 64.1 percent White, 24.5 percent African-American and 9.4 
percent Hispanic. The population of North Lake County, with its principal industrial centers of East Chicago, Hammond and Gary consists primarily of a diverse mix of lower to middle income working class families of European, African American and Hispanic ancestry. More than $30 \%$ of the East Chicago population is Hispanic in origin, Gary is primarily African American and Hammond is mostly Caucasian with a fast growing Hispanic population. Of the total number below poverty in Lake County, 79 percent live in three cities, with 13.3 percent in East Chicago, 52.4 in Gary, and 13.3 in Hammond. Factors associated with pervasive poverty continue to plague the county. These problems include high rates of single-parent headed households, teen mental health and substance abuse problems, juvenile delinquency, child abuse, teen pregnancy, infant mortality, poor nutrition, low levels of academic achievement, a poorly trained workforce and consumers having little access to technology. The population of human service consumers throughout the county is characterized by the multi-systemic use of services.

The HSITMP has adequately documented the lack of information infrastructure characteristics of human service providers in Lake County. Combined with the pervasive poverty that characterizes the region, human service providers and consumers are challenged to leverage the efficiencies to be realized through the use of internet technologies. Presently, the public library system, the universities, and the some of the schools have developed internet access. Among human service providers, the results from the HSITMP suggest that no more than 15 percent of agency employees have direct internet access.

\section{Strategies for Overcoming Barriers to Access}

The primary vehicle for overcoming the barriers related to accessing the internet based technology used in this project will involve the ongoing end-user development activities of the Workgroup and the onground activities of the implementation specialists hired for the project. The Workgroup will provide monthly support activities for end-users through on-site sessions and video-conferencing technologies. The implementation specialists will focus on end users from both the provider and consumer communities by conducting weekly development activities, one-on-one sessions in consumer homes, and fielding inquiries directed to their offices. Implementation specialists will be available for ongoing support. For consumers, a group of parent/consumer peer advisors will be trained to support other parents in the use of technology being implemented in the project and a local user-group will be formed for provider endusers.

\section{Evaluation and Documentation}

\section{Research Questions}

The primary questions in the project evaluation relate to the degree to which technology is implemented and human service delivery is improved as a function of the project. Questions will include but are not limited to the following: How has the quality of the human services changed as a result of the initiative? What is the impact of peer consultation on buy-in? What is the impact of increased access to computers on consumer participation and their satisfaction with services? What is the impact of computer access upon the employability of adults and the academic achievement of students? Have the development of rules and standards resulted in increased data exchange between providers and consumers? How has the knowledge base improved related to the use of technology? What is the satisfaction level of end-users related to their use of technology? 


\section{Evaluation Strategy}

The evaluation strategy used in this project will involve both process and outcome evaluation methods. Process evaluation will document the implementation of the initiative through the use of observation and documentation of meeting and training activities, minutes from meetings, project logs, and other qualitative techniques. Quantitative methods used in the evaluation will include criterion based measures of technology knowledge, measures of social service effectiveness and satisfaction, and the monitoring of network usage. Where possible, control and experimental groups may be employed in the context of the CMHI evaluation creating a controlled evaluation on indicators such as consumer satisfaction.

\section{Data Collection and Analysis}

Where possible, a within subjects groups design will be used in the collection of pre-test and post-test data. Collection of data will take place by the Research Coordinator and consumer data collectors trained to collect data for the CMHI. The evaluation team will compile a computer-assisted content analysis of process evaluation documentation with a special emphasis on the way that agencies implement and adhere to the rules and standards. Multivariate methods will in the quantitative analysis.

\section{Conclusion}

The Family Access Project will provide the technological solution necessary to assist in the basic organizational change needed within the human service system in Lake County, Indiana. While the challenges related to project implementation loom large, an incremental approach to change will result in the desired result. Given the consumercentric approach taken by project planners, the Family Access Project is a novel use of technology to improve the quality of life for residents of the region. Successful implementation of the project will result in replication across the United States and beyond.

\section{Biographies}

Thomas Pavkov is Director of the Head Start XXI Resource Center and an Associate Professor of Psychology. Dr. Pavkov has served as an academic advisor and instructor in the areas of statistics, research methods, child development, and adolescent development. He is also a research associate with the Chapin Hall Center for Children at the University of Chicago. In addition, he directs the operations of the Lake County Child Care Resource and Referral, and is the Evaluation Director for the Child Mental Health Initiative for Northwest Indiana.

Charles Winer is an associate professor at Purdue University Calumet, where he teaches database and senior capstone courses in the Information Systems and Computer Programming department. Professor Winer has authored several papers on database systems, e-commerce and distance learning. In addition, he recently presented a keynote plenary address on The Internet, E-Commerce \& Database Methods at the $5^{\mathrm{TH}}$ World Multiconference on Systemics, Cybernetics and Informatics (SCI) \& Information Systems Analysis and Syntheses (ISAS) Conference 2000 in Orlando, Florida 